\title{
Avaliação da linguagem oral e escrita no pré-escolar e nos primeiros anos de escolaridade
}

\author{
Joana Batalha, Maria Lobo, Antónia Estrela \& Bruna Bragança
}

Centro de Linguística da Universidade Nova de Lisboa

\begin{abstract}
In this article, we present an assessment instrument aimed at diagnosing oral language and reading and writing skills in children attending pre-school (5 years) and the early years of primary school. The instrument was mainly designed for the school context, and it was developed in collaboration with kindergarten educators and primary teachers who participated in PIPALE - Preventive Intervention Project for Reading and Writing, a project which is integrated in the National Program for the Promotion of School Success. The instrument covers the assessment of phonological and syntactic awareness, comprehension of syntactic structures, early literacy, and reading and writing skills (word reading, word and sentence writing, text comprehension, and text production). Besides offering a detailed description of the structure and tasks of the instrument, the present study includes the results of the first implementation of this tool to a total of 495 students in pre-school, first grade and second grade. The results show significant differences between the three groups (pre-school, first grade and second grade) in phonological awareness (identification of initial syllable, initial phoneme and final rhyme) and between the younger groups and the second graders in syntactic awareness (acceptability judgement task) and early literacy skills. As for reading and writing skills, the results show better performance in reading tasks than in writing tasks, a strong significant correlation between phonological awareness and word reading and word writing, and between literacy skills and word reading and writing. We also found a milder correlation between syntactic awareness and reading comprehension, as well as text writing. These results suggest that the instrument is effective for an early diagnosis and early intervention of reading and writing skills.
\end{abstract}

Keywords: language assessment, phonological awareness, syntactic awareness, early reading and writing, emergent literacy

Palavras-chave: avaliação da linguagem, consciência fonológica, consciência sintática, iniciação à leitura e à escrita, literacia emergente

\section{Introdução}

As competências de leitura e escrita têm sido identificadas como uma área em que os alunos portugueses evidenciam maiores dificuldades no início da escolaridade, sendo apontadas por professores e outros agentes educativos como uma das principais causas de insucesso e de abandono escolar (Rodrigues et al., 2017; Verdasca et al., 2019). O impacto das dificuldades relacionadas com a leitura e a escrita não parece manifestar-se apenas no contexto escolar, havendo evidência de que, a longo prazo, estas dificuldades contribuem negativamente para condições de bem-estar e de independência económica na idade adulta (Smart et al. 2017; Pape et al., 2011).

O diagnóstico precoce de eventuais dificuldades na aprendizagem da leitura e da escrita tem um papel importante para o sucesso no desenvolvimento destas competências, o que torna necessária a existência de instrumentos adequados à sua avaliação, em particular no contexto escolar. 
A avaliação de competências na modalidade escrita da linguagem não poderá ser dissociada de uma avaliação da linguagem oral, assumindo-se que o desenvolvimento da linguagem oral é facilitador da aprendizagem do código escrito. Neste contexto, usamos a expressão "linguagem oral” não apenas para referir o conhecimento linguístico implícito, isto é, o conhecimento intuitivo que os falantes têm da sua língua materna, que é desenvolvido naturalmente desde o nascimento e que lhes permite compreender e produzir enunciados, mas também a consciência linguística, a capacidade espontânea para refletir sobre as estruturas da língua, em particular para identificar unidades linguísticas e para manipular, de forma deliberada, unidades e regras da gramática (Duarte, 2008).

A evidência empírica das últimas décadas sobre a importância da consciência linguística para a aprendizagem da linguagem escrita é muito vasta e encontra-se repercutida nos documentos orientadores atualmente em vigor para o ensino do Português desde o nível pré-escolar (Silva, 2016; DGE, 2018). Nas Orientações Curriculares para a Educação Pré-escolar (Silva, 2016), no domínio da linguagem oral e abordagem à escrita, são consideradas duas componentes em que devem ser promovidas aprendizagens em idade pré-escolar: a comunicação oral e a consciência linguística. Relativamente à consciência linguística, fazem parte das aprendizagens a promover: "tomar consciência gradual sobre diferentes segmentos orais que constituem as palavras (consciência fonológica); identificar diferentes palavras numa frase (consciência da palavra); identificar se uma frase está correta ou incorreta e eventualmente corrigi-la, explicitando as razões dessa correção (consciência sintática)" (Silva, 2016: 65). Relativamente ao 1. ${ }^{\circ}$ ciclo, nas Aprendizagens Essenciais (DGE, 2018), são preconizadas, por exemplo, aprendizagens que permitam a "consciencialização de elementos e estruturas fonológicas como fonemas, sílabas, palavras" ou a "consciencialização do modo como a unidade frase se organiza em torno de palavras-centro" (DGE, 2018: 11).

A criação de instrumentos de avaliação da linguagem é uma tarefa bastante complexa. Em Portugal, é relativamente recente o interesse pela avaliação da linguagem e, em particular, pela criação de instrumentos de avaliação. No que se refere à avaliação da linguagem oral, Viana et al. (2017) mostram que o número de instrumentos disponíveis para a população portuguesa é escasso, mas tem vindo a aumentar, identificando quase 30 provas disponíveis para o português europeu, entre provas originais e adaptadas. Quanto à avaliação da linguagem escrita, Alves e Carvoeiro (2019) identificam 28 instrumentos de avaliação relacionados com a modalidade escrita da linguagem, incidindo a maior parte destes instrumentos sobre as competências de leitura.

Apesar do maior número e diversidade de instrumentos, pode constatar-se que, de um modo geral, os instrumentos já disponíveis: (i) avaliam competências parciais, isto é, poucos instrumentos incluem avaliação de um conjunto mais abrangente de competências; (ii) alguns domínios têm sido pouco contemplados, por exemplo o domínio da sintaxe em instrumentos de avaliação da linguagem oral ou a competência escrita nos instrumentos de avaliação da linguagem escrita; (iii) poucos instrumentos foram concebidos propositadamente para o contexto escolar, com a colaboração e validação de educadores e professores.

Neste artigo, pretende-se apresentar um instrumento de avaliação que visa o diagnóstico de competências da linguagem oral e da leitura e da escrita em crianças a frequentar o pré-escolar (5 anos) e os anos iniciais do $1 .^{\circ}$ ciclo (1. ${ }^{\circ}$ e $2 .^{\circ}$ anos de escolaridade). O instrumento que se apresenta distingue-se pelo facto de integrar tanto a avaliação de conhecimentos e capacidades da linguagem oral (incluindo a consciência linguística, nos domínios fonológico e sintático) como da linguagem escrita (incluindo competências de literacia emergente), sendo destinado a um público que abrange crianças em idade pré-escolar e em idade escolar. O instrumento foi concebido, fundamentalmente, para o contexto educativo, colmatando uma necessidade identificada junto de educadores de infância e de professores de $1 .^{\circ}$ ciclo para proceder a um diagnóstico de competências relacionadas com a leitura e a escrita em fases que antecedem ou em que se dá início a aprendizagem formal destas competências. Ao contrário de outros instrumentos, que se destinam especificamente a fins terapêuticos, este instrumento é mais abrangente, permitindo a identificação de perfis de aprendizagem e de problemas que decorrem de dificuldades de ensino-aprendizagem. O instrumento foi desenvolvido em colaboração com 
educadores de infância e professores de $1 .^{\circ}$ ciclo em contexto de formação no âmbito do PIPALE - Projeto de Intervenção Preventiva para a Aprendizagem da Leitura e da Escrita, um projeto desenvolvido pelo Centro de Linguística da Universidade Nova de Lisboa e apoiado pelo Programa Nacional de Promoção do Sucesso Escolar e que tem como principal finalidade melhorar, desde uma idade precoce, os níveis de qualidade das aprendizagens em português como língua materna, em particular ao nível das competências de leitura e escrita.

\section{Descrição do instrumento de avaliação}

O instrumento de diagnóstico do PIPALE foi concebido tendo em consideração instrumentos de avaliação da linguagem oral e da linguagem escrita já disponíveis para o português europeu. Em particular, foram tidas em conta tarefas e provas que têm vindo a ser utilizadas na avaliação da consciência linguística (Freitas, Gonçalves \& Duarte, 2010; Cardoso \& Castro, 2012; Perdigão, 2015) e na avaliação de competências iniciais de leitura e escrita em Portugal, particularmente a Prova de Reconhecimento de Palavras (Viana \& Ribeiro, 2010), as Provas de Rastreio de 1. ${ }^{\circ}$ ano do projeto Conhecer, Atuar e Mudar (Viana et al., 2018) e as Provas de Aferição de $2 .^{\circ}$ ano do Instituto de Avaliação Educativa (IAVE).

O instrumento é constituído por materiais destinados aos alunos (quatro Cadernos) e materiais para o educador/professor: um Manual de aplicação e classificação, um Guião áudio e um conjunto de ficheiros áudio (em formato mp4).

O Manual de aplicação e classificação contém quatro secções: (i) caracterização dos Cadernos; (ii) orientações para aplicação; (iii) critérios de classificação; (iv) interpretação dos resultados. O Guião áudio contém a transcrição das instruções e estímulos linguísticos apresentados nos ficheiros áudio.

Cada um dos quatro Cadernos avalia diferentes domínios da linguagem oral e da linguagem escrita e dirige-se a diferentes públicos, conforme apresentado na Tabela 1.

\begin{tabular}{|c|c|c|c|}
\hline & O que avalia & Tarefas & A quem se destina \\
\hline Caderno 1 & $\begin{array}{l}\text { Consciência fonológica } \\
\text { Consciência de palavra }\end{array}$ & $\begin{array}{l}\text { Identificação de sílaba } \\
\text { Identificação de rima } \\
\text { Identificação de fonema } \\
\text { Identificação de número de palavras de uma } \\
\text { frase }\end{array}$ & $\begin{array}{l}\text { Pré-escolar } 5 \text { anos } \\
1 .^{\circ} \text { ano } \\
2 .^{\circ} \text { ano }\end{array}$ \\
\hline Caderno 2 & $\begin{array}{l}\text { Conhecimento sintático } \\
\text { Consciência sintática }\end{array}$ & $\begin{array}{l}\text { Compreensão de passivas, de relativas de } \\
\text { objeto e de interrogativas de objeto } \\
\text { Juízo de aceitabilidade de frases com } \\
\text { problemas de concordância e de ordem de } \\
\text { palavras }\end{array}$ & $\begin{array}{l}\text { Pré-escolar } 5 \text { anos } \\
\text { 1. }{ }^{\circ} \text { ano } \\
2 .^{\circ} \text { ano }\end{array}$ \\
\hline Caderno 3A & $\begin{array}{l}\text { Conhecimentos emergentes } \\
\text { sobre unidades da escrita }\end{array}$ & $\begin{array}{l}\text { Reconhecimento de letras vs. números e } \\
\text { outros símbolos } \\
\text { Reconhecimento do que é uma palavra vs. } \\
\text { não palavra } \\
\text { Reconhecimento da direcionalidade da } \\
\text { escrita }\end{array}$ & $\begin{array}{l}\text { Pré-escolar } 5 \text { anos } \\
1 .^{\circ} \text { ano } \\
2 .^{\circ} \text { ano }\end{array}$ \\
\hline Caderno 3B & $\begin{array}{l}\text { Conhecimentos iniciais sobre } \\
\text { leitura e escrita }\end{array}$ & $\begin{array}{l}\text { Reconhecimento de letra maiúscula e } \\
\text { minúscula } \\
\text { Reconhecimento de letra de imprensa e } \\
\text { manuscrita } \\
\text { Reconhecimento das letras do alfabeto }\end{array}$ & $\begin{array}{l}1 .^{\circ} \text { ano } \\
2 .^{\circ} \text { ano }\end{array}$ \\
\hline
\end{tabular}




\begin{tabular}{|l|l|l|l|}
\hline Caderno 4 & $\begin{array}{l}\text { Competências de leitura e } \\
\text { escrita }\end{array}$ & $\begin{array}{l}\text { Leitura de palavras } \\
\text { Escrita de palavras e de frases } \\
\text { Compreensão de texto narrativo e de texto } \\
\text { expositivo } \\
\text { Escrita de texto narrativo }\end{array}$ & $2 .^{\circ}$ ano \\
& & & \\
\hline
\end{tabular}

Tabela 1. Domínios e destinatários do instrumento.

Os Cadernos 1, 2 e 3A destinam-se a todas as crianças; o Caderno 3B destina-se a crianças do $1 .^{\circ}$ e $2 .^{\circ}$ anos de escolaridade; o Caderno 4 destina-se a crianças do $2 .^{\circ}$ ano de escolaridade.

O Caderno 1 avalia o desenvolvimento da consciência fonológica, incluindo consciência silábica, consciência intrassilábica, consciência fonémica, e consciência de palavra. O Caderno 2 avalia, no domínio do conhecimento sintático, a compreensão de estruturas sintáticas de desenvolvimento tardio (passivas, relativas de objeto e interrogativas de objeto com restrição lexical) e, no domínio da consciência sintática, a capacidade de avaliar a boa ou má formação de frases simples. O Caderno 3A avalia conhecimentos emergentes sobre unidades da escrita, incluindo distinção entre letras e outros símbolos (números e sinais) e reconhecimento do que pode ou não ser uma palavra escrita. O Caderno 3B contém itens que avaliam conhecimentos iniciais sobre leitura e escrita, incluindo distinção entre letras e outros símbolos (números e sinais), reconhecimento do que pode ou não ser uma palavra escrita, conhecimento dos nomes das letras, reconhecimento de tipos de letras (impressa ou manuscrita, maiúscula ou minúscula), conhecimento sobre a direcionalidade da escrita e conhecimento sobre fronteira de palavra escrita. O Caderno 4 avalia competências de leitura e de escrita, incluindo conhecimento de correspondências fonema-grafema e de regras de ortografia básicas, compreensão de texto e escrita de texto.

O Caderno 1 é constituído por 16 itens de teste e quatro itens de exemplo e está organizado em quatro grupos (de A a D). O Grupo A avalia consciência silábica através de uma tarefa de seleção de imagens correspondentes a palavras que começam com a mesma sílaba. Procurou-se incluir itens com diferentes graus de dificuldade quanto ao formato silábico (CV e CVC) e quanto à extensão silábica das palavras (duas ou três sílabas), assim como palavras de uso frequente e facilmente reconhecíveis através de imagens. Esta tarefa inclui quatro itens de teste e um item de exemplo, reproduzido na Figura 1.

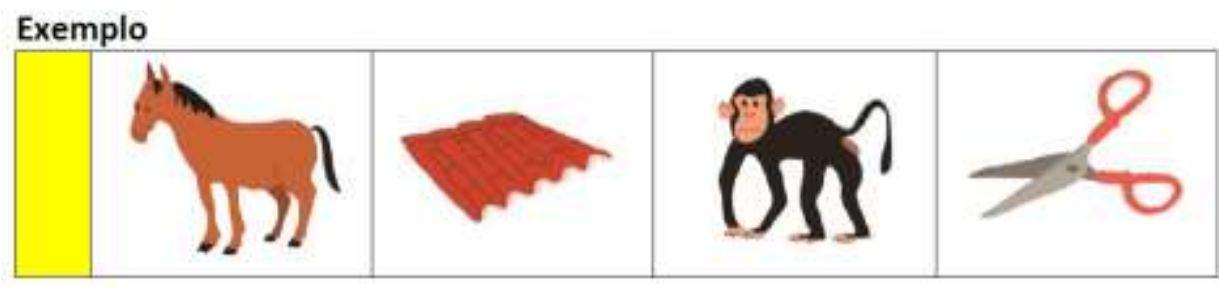

Figura 1. Item de exemplo do Caderno 1, grupo A.

A instrução para os itens, a fornecer em gravação áudio, é a seguinte: Ouve com atenção e rodeia as imagens das duas palavras que começam da mesma maneira. No item de exemplo, são ouvidas as palavras cavalo, telhado, macaco e tesoura.

O Grupo B avalia consciência intrassilábica através de uma tarefa de seleção de imagens relativas a palavras que rimam. Para se distinguir rima métrica e rima enquanto constituinte da sílaba, optou-se por incluir apenas palavras agudas, em que há coincidência entre rima métrica e rima intrassilábica. Evitaram-se casos em 
que as palavras terminam na mesma sílaba, tendo-se contemplado apenas palavras que têm unicamente a mesma rima intrassilábica final. Esta tarefa inclui quatro itens de teste e um item de exemplo, apresentado na Figura 2.

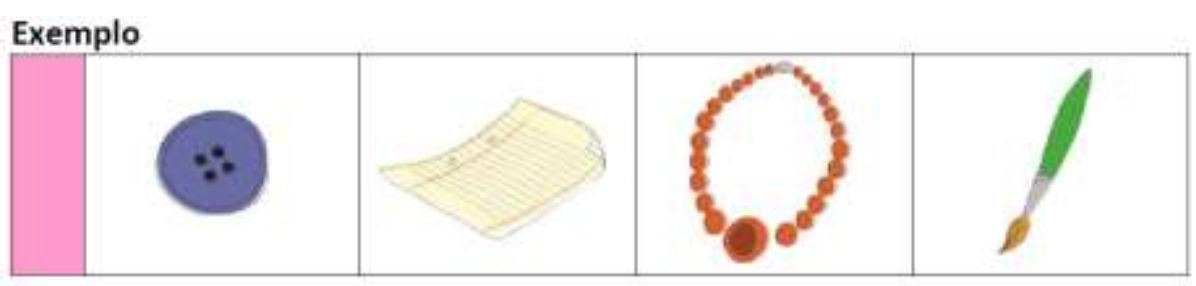

Figura 2. Item de exemplo do Caderno 1, grupo B.

A instrução para os itens, a fornecer através de gravação áudio, é a seguinte: Ouve com atenção e rodeia as imagens das duas palavras que terminam da mesma maneira. No item de exemplo, são ouvidas as palavras botão, papel, colar e pincel.

O Grupo C avalia consciência fonémica através de uma tarefa de seleção de imagens relativas a palavras que começam com o mesmo fonema. Procurou-se abranger itens com diferentes graus de dificuldade, incluindo identificação de palavras iniciadas por fricativas, líquidas, nasais e oclusivas. Esta tarefa inclui quatro itens de teste e um item de exemplo, apresentado na Figura 3.

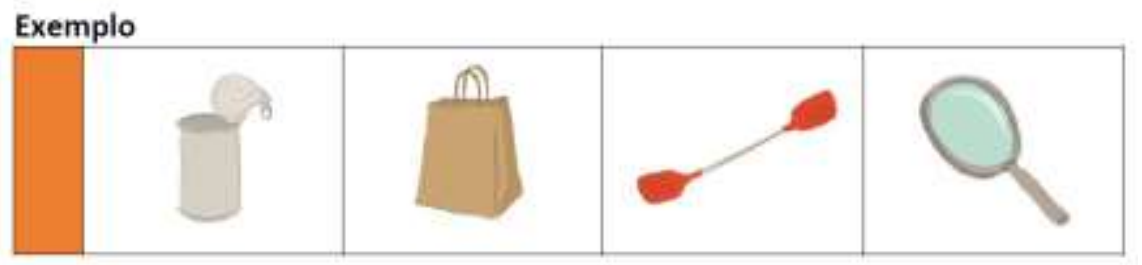

Figura 3. Item de exemplo do Caderno 1, grupo C.

A instrução para os itens, a fornecer em gravação áudio, é a seguinte: Ouve com atenção e rodeia as imagens das duas palavras que começam com o mesmo som. No item de exemplo, são ouvidas as palavras lata, saco, remo e lupa.

O Grupo D avalia consciência de palavra através de uma tarefa de seleção que requer a identificação de número de palavras de uma frase. Procurou-se incluir itens com diferentes graus de dificuldade, incluindo frases de diferentes extensões e palavras gramaticais de dificuldade variável (determinantes tónicos e átonos). Esta tarefa inclui quatro itens de teste e um item de exemplo, reproduzido na Figura 4.

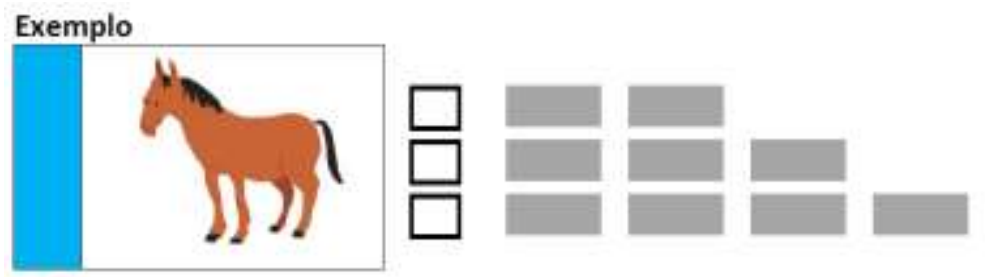

Figura 4. Item de exemplo do Caderno A, grupo D. 
A instrução para os itens, a fornecer em gravação áudio, é a seguinte: Ouve a frase e conta as palavras. Depois faz uma cruz no número certo de retângulos. No item de exemplo, é ouvida a frase O cavalo parou.

O Caderno 2 é constituído por 21 itens de teste e três itens de exemplo e está organizado em três grupos (de A a C).

O Grupo A avalia compreensão de estruturas sintáticas de desenvolvimento tardio, nomeadamente compreensão de frases passivas. Incluíram-se três frases passivas reversíveis. A tarefa consiste na seleção de uma de três imagens em função de uma frase ouvida. Esta tarefa inclui três itens de teste e um item de exemplo, sendo um dos itens de teste reproduzido na Figura 5.

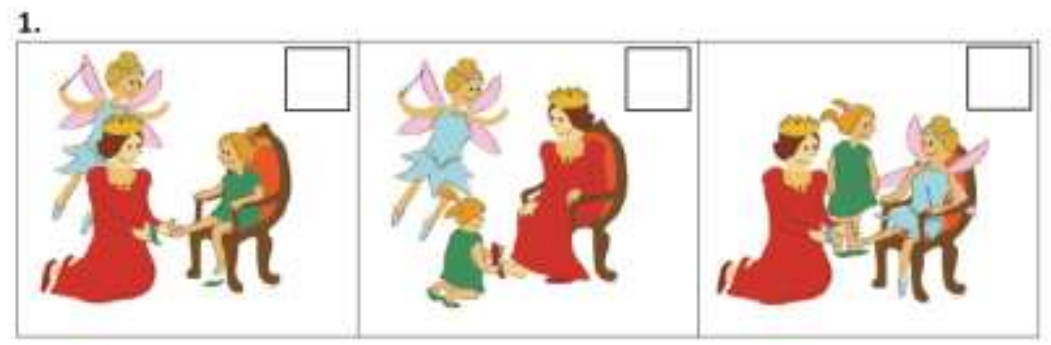

Figura 5. Item de teste do Caderno 2, grupo A.

Para o item apresentado, a instrução, a fornecer em gravação áudio, é a seguinte: Vais ouvir uma frase sobre uma rainha, uma menina e uma fada. Faz uma cruz na imagem certa. A frase apresentada é A rainha está a ser calçada pela menina.

O Grupo B avalia compreensão de estruturas sintáticas de desenvolvimento tardio, nomeadamente compreensão de orações relativas e de frases interrogativas. Incluíram-se três frases que contêm orações relativas de objeto reversíveis e três frases interrogativas de objeto com restrição lexical reversíveis. A tarefa consiste na seleção de um de dois elementos apresentados numa imagem em função de uma frase ouvida. Esta tarefa inclui seis itens de teste (três com frases relativas e três com interrogativas) e um item de exemplo. A Figura 6 apresenta um dos itens de teste com frase relativa e a Figura 7 apresenta um dos itens de teste com frase interrogativa.

A instrução, a fornecer em gravação áudio, é a seguinte: Ouve a frase e faz uma cruz no quadrado certo. A frase apresentada para o exemplo da Figura 6 é Escolhe o gato que o cão está a lamber e para o exemplo da Figura 7 é Que carro é que o trator está a puxar?

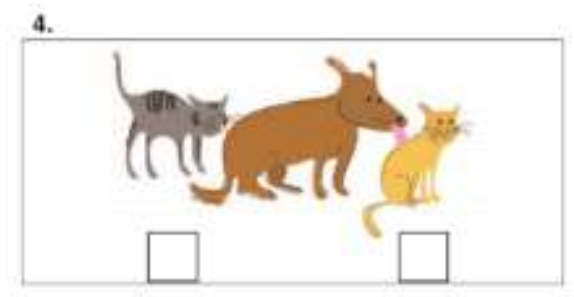

Figura 6. Item de teste do Caderno 2, grupo B. 


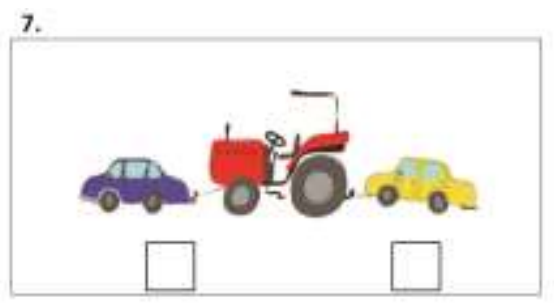

Figura 7. Item de teste do Caderno 2, grupo B.

O Grupo C avalia consciência sintática através de uma tarefa de juízo de aceitabilidade, tendo a criança de selecionar um de dois símbolos para certo/errado em função de uma frase ouvida. As frases a avaliar incluem quatro frases bem formadas e oito frases mal formadas. Destas, quatro têm problemas de ordem de palavras com diferentes graus de dificuldade (ordem Nome-Determinante, ordem Verbo principal-Verbo auxiliar, ordem Adjetivo-Nome, ordem Advérbio-Verbo) e quatro têm problemas de concordância, incluindo concordância nominal (falta de concordância em género entre Determinante e Nome e falta de concordância em número entre Determinante e Nome) e concordância verbal (falta de concordância em número entre sujeito e verbo). Esta tarefa inclui doze itens de teste e um item de exemplo, apresentado na Figura 8.

A instrução para os itens, a fornecer em gravação áudio, é a seguinte: Neste jogo, vamos brincar ao certo ou errado e vamos ajudar o Grumpf. O Grumpf veio de outro planeta e não sabe falar bem a nossa língua. Vamos ajudá-lo a aprender! Ouve bem o que o Grumpf diz. Ele vai dizer uma frase duas vezes. Quando ele falar bem, vais rodear a cara alegre. Quando ele falar mal, vais rodear a cara triste. No item de exemplo, a frase ouvida é Eu é alto.

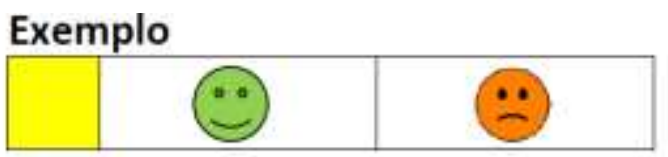

Figura 8. Item de exemplo do Caderno 2, grupo C.

O Caderno 3A é constituído por quatro itens de teste e um item de exemplo. A tarefa usada consiste numa tarefa de seleção múltipla que requer a distinção de letras e outros símbolos e a identificação do que é uma possível palavra escrita de um conjunto de três opções.

O Caderno 3B contém 31 itens de teste e dois itens de exemplo e está organizado em dois grupos (B e C). O Grupo B avalia o conhecimento dos nomes das letras através de uma tarefa de seleção múltipla com três opções. Incluíram-se 23 letras. Para as consoantes, as opções em alternativa à letra alvo são uma vogal e uma consoante cujo nome difere claramente do da letra alvo; para as vogais, são uma vogal e uma consoante. O Grupo C avalia reconhecimento de tipos de letras (impressa ou manuscrita, maiúscula ou minúscula), conhecimento sobre a direcionalidade da escrita e conhecimento sobre fronteira de palavra escrita através de uma tarefa de seleção múltipla com três opções.

A Figura 9 apresenta um item de teste do Caderno 3. A instrução para este item, a fornecer em gravação áudio, é a seguinte: Na linha do verde, rodeia a letra.

2.

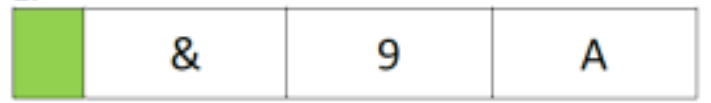

Figura 9. Item de exemplo do Caderno 3, grupo A. 
O Caderno 4 é constituído por 26 itens de teste e um item de exemplo e está organizado em quatro grupos (de A a D). Os dois primeiros grupos avaliam palavras e frases e os dois últimos grupos avaliam texto. Os Grupos A e C avaliam leitura e os Grupos B e D avaliam escrita.

O Grupo A avalia conhecimento de correspondências fonema-grafema e de regras de ortografia básicas numa tarefa de leitura de palavras. Nesta tarefa, a criança ouve uma palavra e tem de selecionar a palavra escrita que lhe corresponde de um conjunto de três opções. Incluíram-se 10 itens: 5 contêm dissílabos e 5 contêm trissílabos. Em cada item, as opções são graficamente e/ou fonologicamente próximas. Na Figura 10, é reproduzido o item de exemplo.

\begin{tabular}{|l|l|l|l|l|l|l|}
\hline Exemplo & A & torrada & B & tourada & C & tomada \\
\hline
\end{tabular}

Figura 10. Item de exemplo do Caderno 4, grupo A.

O Grupo C avalia compreensão de texto, considerando diferentes subprocessos da compreensão (compreensão literal, compreensão inferencial e reorganização). Foram incluídos dois textos com extensão entre 90 e 140 palavras: um texto narrativo, seguido de três itens de seleção múltipla, e um texto expositivo, seguido de um item de completamento de um esquema.

O Grupo B avalia conhecimento de correspondências fonema-grafema e de regras de ortografia básicas numa tarefa de escrita de palavras. São incluídas 10 palavras e duas frases. O Grupo D avalia a escrita de um texto a partir de uma sequência de três imagens através de um item de construção. A sequência de imagens induz a produção de um texto de caráter narrativo. A extensão máxima dos textos a produzir é de dez linhas.

\section{Procedimentos de implementação}

O instrumento PIPALE foi implementado no início do ano letivo 2019-2020 em três agrupamentos de escolas públicas do município de Sesimbra, no distrito de Setúbal, a três grupos de participantes: crianças a frequentar o último ano de pré-escolar (iniciaram o ano letivo com 5 anos), alunos do $1 .^{\circ}$ ano e alunos do $2 .^{\circ}$ ano de escolaridade, de acordo com a distribuição apresentada na Tabela 2.

\begin{tabular}{|l|l|l|l|}
\hline Pré 5 & $\mathbf{1 .}^{\mathbf{0}}$ ano & $\mathbf{2 .}^{\mathbf{0}}$ ano & Total \\
\hline 153 & 165 & 177 & 495 \\
\hline
\end{tabular}

Tabela 2. Participantes do estudo por grupo escolar.

Considera-se para o presente estudo uma amostra de 495 participantes falantes de português europeu como língua materna, sem diagnóstico de perturbações cognitivas e linguísticas (tendo por base a recolha de informação sobre a não implementação de medidas seletivas ou adicionais) e cujos Encarregados de Educação deram consentimento para divulgação de dados para efeitos de investigação.

O instrumento foi aplicado em grupos ou em grupo-turma pelos educadores de infância e professores titulares de turma, nas suas salas, de acordo com as orientações do Manual que acompanha o instrumento e com apoio da equipa de investigadores.

Os Cadernos foram disponibilizados aos participantes em suporte papel e a cores. Foram usados ficheiros áudio mp4 com os estímulos linguísticos orais em computadores com colunas existentes nas salas. 
A classificação dos Cadernos foi realizada pelos educadores e professores de acordo com critérios de classificação disponibilizados no Manual numa grelha de registo informatizada.

\section{Apresentação de resultados}

Todas as respostas foram sujeitas a uma análise estatística descritiva e inferencial de modo a verificar se existiam diferenças significativas entre os resultados nos grupos de participantes relativamente às competências avaliadas nos três grupos (Cadernos 1,2 e 3A) ou nos dois grupos de $1 .^{\circ}$ ciclo (Caderno 3B), com identificação de áreas de maior dificuldade.

Os resultados são apresentados por Caderno a partir do número médio de respostas certas. Para se testar se as diferenças entre grupos escolares são estatisticamente significativas (valor $p$ inferior a 0.05), recorreu-se ao teste de Kruskal-Wallis com comparações múltiplas.

Os diferentes grupos de itens de cada Caderno são identificados através de um descritor que corresponde à capacidade ou conhecimento avaliado.

Na Tabela 3, são apresentados os resultados para o Caderno 1, que avalia consciência fonológica (silábica, intrassilábica e fonémica) e consciência de palavra. Pode constatar-se que o grupo de 2..$^{\circ}$ ano apresenta resultados superiores aos de $1 .^{\circ}$ ano em todas as capacidades avaliadas, sendo possível encontrar entre os dois grupos diferenças estatisticamente significativas. Também em relação ao pré-escolar, o grupo de $2{ }^{\circ}$ ano obteve uma média de acerto superior quanto à identificação de palavras com sílabas iniciais iguais, de palavras que rimam e de palavras com sons iniciais iguais, mas não quanto à identificação das palavras de uma frase escutada. A diferença mais significativa entre estes dois grupos encontra-se na identificação de palavras com sons iniciais iguais $(p<0.0001)$. Contrariamente ao que poderia ser esperado, o grupo de $10^{\circ}$ ano apresenta médias inferiores ao grupo de pré-escolar, com diferenças estatisticamente significativas quanto à identificação de palavras com sílabas iniciais iguais $(p=0.0091)$, de palavras com sons iniciais iguais $(p=0.0019)$ e de palavras de uma frase escutada $(p<0.0001)$. O facto de o grupo de $1 .^{\circ}$ ano incluir crianças que não frequentaram o pré-escolar e a reorganização de conhecimentos que ocorre nesta fase, associada a um contacto formal com a linguagem escrita, poderão ser fatores explicativos dos resultados obtidos.

\begin{tabular}{|l|rrrr|rrrrrrrr|}
\hline & \multicolumn{4}{|c|}{ Pré } & \multicolumn{4}{c|}{$\mathbf{1 .}^{\mathbf{0}}$ ano } & \multicolumn{3}{c|}{$\mathbf{2 .}^{\mathbf{0}}$ ano } \\
\cline { 2 - 12 } & $M$ & DP & Min & Max & M & DP & Min & Max & M & DP & Min & Max \\
\hline $\begin{array}{l}\text { Identifica palavras com } \\
\text { sílabas iniciais iguais }\end{array}$ & 2.88 & 1.34 & 0 & 4 & 2.51 & 1.35 & 0 & 4 & 3.47 & 1.00 & 0 & 4 \\
\hline $\begin{array}{l}\text { Identifica palavras que } \\
\text { rimam }\end{array}$ & 2.74 & 1.34 & 0 & 4 & 2.60 & 1.38 & 0 & 4 & 3.17 & 1.16 & 0 & 4 \\
\hline $\begin{array}{l}\text { Identifica palavras com } \\
\text { sons iniciais iguais }\end{array}$ & 2.34 & 1.51 & 0 & 4 & 1.83 & 1.30 & 0 & 4 & 3.08 & 1.20 & 0 & 4 \\
\hline $\begin{array}{l}\text { Identifica palavras de uma } \\
\text { frase escutada }\end{array}$ & 3.03 & 1.18 & 0 & 4 & 2.32 & 1.27 & 0 & 4 & 2.75 & 1.34 & 0 & 4 \\
\hline
\end{tabular}

Tabela 3. Resultados por ano de escolaridade em cada domínio do Caderno 1.

A Tabela 4 apresenta os resultados para o Caderno 2, que avalia conhecimento sintático de estruturas frásicas complexas (passivas, relativas e interrogativas) e consciência sintática (juízos de aceitabilidade de frases). Relativamente ao conhecimento sintático, as médias obtidas evidenciam que, globalmente, não houve dificuldades na compreensão das estruturas testadas. As diferenças entre grupos só são estatisticamente 
significativas entre o pré-escolar e o $2^{\circ}$ ano quanto às relativas e às interrogativas, não se registando diferenças significativas entre pré e $1 .^{\circ}$ ou entre $1 .^{\circ}$ e $2 .^{\circ}$.

Já no que se refere à consciência sintática, há diferenças significativas com valores robustos $(p<0.0001)$ entre pré e $2 .^{\circ}$ e entre $1 .^{\circ}$ e $2 .^{\circ}$ tanto no reconhecimento de frases mal formadas (com problemas de concordância e de ordem de palavras) como no reconhecimento de frases bem formadas. Já entre pré e $1 .^{\circ}$ ano não foram encontradas diferenças significativas. Relativamente às frases mal formadas, os juízos que envolveram frases com problemas de ordem de palavras suscitaram maior dificuldade em todos os grupos, sendo as médias inferiores às obtidas no reconhecimento de frases com problemas de concordância.

\begin{tabular}{|c|c|c|c|c|c|c|c|c|c|c|c|c|}
\hline & \multicolumn{4}{|c|}{ Pré } & \multicolumn{4}{|c|}{$1 .^{\circ}$ ano } & \multicolumn{4}{|c|}{$2 .^{\circ}$ ano } \\
\hline & $M$ & $D P$ & Min & Max & $M$ & $D P$ & Min & Max & $M$ & $D P$ & Min & Max \\
\hline $\begin{array}{l}\text { Compreende } \\
\text { estruturas frásicas } \\
\text { (passivas) }\end{array}$ & 2.48 & 0.855 & 0 & 3 & 2.56 & 0.775 & 0 & 3 & 2.74 & 0.578 & 0 & 3 \\
\hline $\begin{array}{l}\text { Compreende } \\
\text { estruturas frásicas } \\
\text { (relativas) }\end{array}$ & 2.72 & 0.624 & 0 & 3 & 2.81 & 0.528 & 0 & 3 & 2.90 & 0.358 & 0 & 3 \\
\hline $\begin{array}{l}\text { Compreende } \\
\text { estruturas frásicas } \\
\text { (interrogativas) }\end{array}$ & 2.48 & 0.773 & 0 & 3 & 2.65 & 0.606 & 0 & 3 & 2.78 & 0.441 & 1 & 3 \\
\hline $\begin{array}{l}\text { Reconhece frases } \\
\text { mal formadas } \\
\text { (concordância) }\end{array}$ & 2.97 & 1.27 & 0 & 4 & 3.11 & 1.05 & 0 & 4 & 3.75 & 0.521 & 1 & 4 \\
\hline $\begin{array}{l}\text { Reconhece frases } \\
\text { mal formadas } \\
\text { (ordem de palavras) }\end{array}$ & 2.60 & 1.42 & 0 & 4 & 2.74 & 1.24 & 0 & 4 & 3.63 & 0.755 & 0 & 4 \\
\hline $\begin{array}{l}\text { Reconhece frases } \\
\text { bem formadas }\end{array}$ & 2.58 & 1.51 & 0 & 4 & 2.38 & 1.27 & 0 & 4 & 3.36 & 0.769 & 1 & 4 \\
\hline
\end{tabular}

Tabela 4. Resultados por ano de escolaridade em cada domínio do Caderno 2.

Os resultados do Caderno 3 (3A e 3B) são apresentados na Tabela 5. Recorde-se que o Caderno 3B é realizado apenas pelos grupos de $1 .^{\circ}$ ciclo, já que avalia conhecimentos iniciais de leitura e escrita.

Relativamente à primeira capacidade avaliada, distinção entre letras, números e outros símbolos, pode observar-se uma progressão do pré ao $2 .^{\circ}$ ano, não se registando diferenças estatisticamente significativas entre pré e $1 .^{\circ}$ ano, mas sendo estatisticamente significativas as diferenças entre pré e $2 .^{\circ}(p<0.0001)$ e entre $1 .^{\circ}$ e $2 .^{\circ}$ $(p<0.0001)$. Os resultados para o reconhecimento do que é uma palavra escrita evidenciam uma progressão do pré ao $2 .^{\circ}$ ano, com diferenças significativas entre pré e $1 .^{\circ}(p=0.00041)$, pré e $2 .^{\circ}(p<0.0001)$ e $1 .^{\circ}$ e $2 .^{\circ}$ anos $(p=0.019)$.

Quanto ao reconhecimento dos nomes das letras, à distinção de tipos de letra e à direcionalidade da escrita, são registadas diferenças significativas robustas $(p<0.0001)$ entre os dois grupos de $1 .^{\circ}$ ciclo, com resultados superiores para o grupo de $2 .^{\circ}$ ano, que atinge médias muito próximas dos valores máximos.

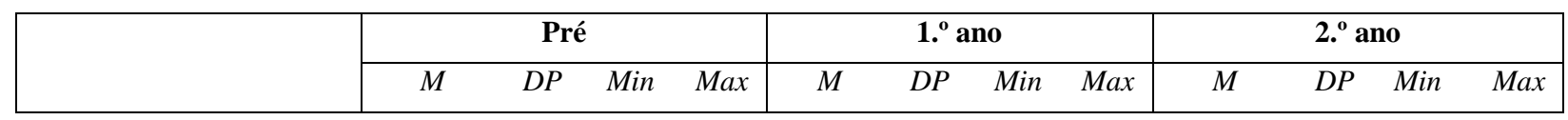




\begin{tabular}{|l|cccc|cccc|ccc|}
\hline $\begin{array}{l}\text { Distingue letras de } \\
\text { números e símbolos }\end{array}$ & 1.50 & 0.747 & 0 & 2 & 1.68 & 0.546 & 0 & 2 & 1.89 & 0.337 & 0 \\
\hline $\begin{array}{l}\text { Reconhece uma palavra } \\
\text { escrita }\end{array}$ & 1.50 & 0.765 & 0 & 2 & 1.76 & 0.603 & 0 & 2 & 1.97 & 0.199 & 0 \\
\hline $\begin{array}{l}\text { Conhece as letras do } \\
\text { alfabeto }\end{array}$ & - & - & - & - & 19.1 & 4.46 & 3 & 23 & 22.6 & 1.44 & 9 \\
\hline $\begin{array}{l}\text { Distingue letra maiúscula } \\
\text { de minúscula }\end{array}$ & - & - & - & - & 1.07 & 0.558 & 0 & 2 & 1.84 & 0.399 & 0 \\
\hline $\begin{array}{l}\text { Distingue letra imprensa } \\
\text { de manuscrita }\end{array}$ & - & - & - & - & 1.31 & 0.608 & 0 & 2 & 1.78 & 0.482 & 0 \\
\hline $\begin{array}{l}\text { Conhece a } \\
\text { direcionalidade da escrita }\end{array}$ & - & - & - & - & 2.42 & 1.29 & 0 & 4 & 3.65 & 0.759 & 0 \\
\hline
\end{tabular}

Tabela 5. Resultados por ano de escolaridade em cada domínio do Caderno 3.

Por último, na Tabela 6, consideram-se os resultados do Caderno 4, que avalia competências de leitura e escrita e é dirigido apenas ao grupo de $2 .^{\circ}$ ano. Ao nível da palavra, a tarefa de escrita de palavras regista uma média mais baixa do que a de leitura de palavras. Relativamente à unidade texto, os resultados evidenciam dificuldades mais acentuadas com a compreensão de texto expositivo e com a escrita de texto.

\begin{tabular}{|l|rrrr|}
\hline & \multicolumn{4}{|c|}{$\mathbf{2 .}^{\circ}$ ano } \\
\cline { 2 - 5 } & \multicolumn{1}{|c|}{ M } & DP & Min & Max \\
\hline $\begin{array}{l}\text { Reconhece a forma escrita de palavras } \\
\text { frequentes }\end{array}$ & 6.85 & 2.98 & 2 & 10 \\
\hline $\begin{array}{l}\text { Escreve palavras frequentes respeitando } \\
\text { regras de ortografia básicas }\end{array}$ & 4.23 & 3.14 & 0 & 10 \\
\hline $\begin{array}{l}\text { Escreve frases curtas respeitando regras de } \\
\text { ortografia básicas }\end{array}$ & 0.22 & 0.506 & 0 & 2 \\
\hline Compreende um breve texto narrativo lido & 1.45 & 0.924 & 0 & 3 \\
\hline $\begin{array}{l}\text { Extrai informação essencial de um texto } \\
\text { expositivo lido }\end{array}$ & 0.22 & 0.418 & 0 & 1 \\
\hline $\begin{array}{l}\text { Escreve um breve texto narrativo a partir de } \\
\text { uma sequência de imagens }\end{array}$ & 2.09 & 1.61 & 0 & 6 \\
\hline
\end{tabular}

Tabela 6. Resultados por ano de escolaridade em cada domínio do Caderno 4.

Para além das diferenças entre grupos, e de modo a perceber-se se podem ser estabelecidas correlações entre as competências avaliadas nos Cadernos 1, 2 e 3 e as competências avaliadas no Caderno 4 no mesmo grupo de alunos, neste caso, o 2. ${ }^{\circ}$ ano, conduziu-se uma análise entre comparadores a partir do número médio de respostas certas de cada participante e procedeu-se ao cálculo do coeficiente de correlação de Kendall, que devolve valores entre - 1 e 1, representando -1 uma fraca associação negativa e 1 uma forte associação positiva entre dois comparadores de interesse. Como se pode observar na Tabela 7, com exceção da comparação Caderno 2 vs. Caderno 4 - Escrita de frases, o coeficiente de Kendall é estatisticamente diferente de 0, com valores de $p$ inferiores a 0.05 em todas as restantes comparações. Os valores do coeficiente sugerem uma maior correlação entre consciência fonológica e escrita e leitura de palavras, com valores de 0,42 e 0,38, respetivamente. 


\begin{tabular}{|c|c|c|c|}
\hline Comparador 1 & Comparador 2 & Coeficiente & Valor-p \\
\hline Caderno 1 & Caderno 4 - Leitura de palavras & 0,383 & $<0,0001$ \\
\hline Caderno 1 & Caderno 4 - Escrita de palavras & 0,419 & $<0,0001$ \\
\hline Caderno 2 & Caderno 4 - Escrita de frases & 0,09 & 0,19 \\
\hline Caderno 2 & Caderno 4 - Leitura de texto & 0,211 & 0,0004 \\
\hline Caderno 2 & Caderno 4 - Escrita de texto & 0,219 & 0,0002 \\
\hline Caderno 3B & Caderno 4 - Leitura de palavras & 0,299 & $<0,0001$ \\
\hline Caderno 3B & Caderno 4 - Escrita de palavras & 0,225 & $<0,0001$ \\
\hline
\end{tabular}

Tabela 7. Comparações entre Caderno 4 e restantes cadernos.

\section{Considerações finais}

Os resultados do presente estudo corroboram evidências obtidas em estudos anteriores que mostram uma correlação positiva entre competências de leitura e escrita e consciência linguística (fonológica e sintática), bem como uma correlação positiva entre competências de leitura e escrita e literacia emergente (representações precoces sobre a linguagem escrita, conhecimento da direcionalidade da escrita, reconhecimento de letras) (Gough \& Tunmer, 1986; Demont \& Gombert, 1996; Rego \& Buarque, 1997; Capovilla, Capovilla \& Soares, 2004; Kirby et al., 2008; Schaars, Segers \& Verhoeven, 2019; entre outros).

Como esperado, a comparação entre os resultados das crianças do pré-escolar, $1 .^{\circ}$ e $2 .^{\circ}$ anos permitiu, globalmente, identificar desenvolvimento nos diferentes domínios da consciência fonológica, sendo o domínio da consciência fonémica aquele em que o desenvolvimento é mais tardio. No domínio de consciência de palavra, contudo, não se verificou o desenvolvimento esperado, o que talvez se possa atribuir ao facto de, no início do primeiro ano de escolaridade, o conhecimento das crianças estar em reorganização pelo foco na representação escrita da língua. Também no domínio da sintaxe, verificámos desenvolvimento na capacidade de fazer juízos de aceitabilidade, com a agramaticalidade decorrente de alterações de ordem de palavras a manifestar mais dificuldades do que a agramaticalidade decorrente de problemas de concordância, na linha do que têm reportado trabalhos anteriores (Perdigão, 2015). No que diz respeito à compreensão de estruturas sintáticas complexas, os resultados mostram já haver, globalmente, uma compreensão razoável de estruturas relativas e interrogativas de objeto e de frases passivas no pré-escolar, estando, contudo, a compreensão destas estruturas ainda em desenvolvimento, o que vai ao encontro do que estudos anteriores têm mostrado (Costa, Lobo \& Silva, 2011; Estrela, 2013; Agostinho, 2020).

Os primeiros resultados obtidos com a aplicação do instrumento PIPALE e as correlações entre os domínios da consciência linguística e as competências de leitura e escrita sugerem ainda que o instrumento tem potencial para antecipar em idade precoce dificuldades de leitura e escrita, permitindo uma intervenção precoce junto de crianças em risco. Para que o instrumento possa funcionar como instrumento de rastreio, será necessário normalizar o instrumento e estabelecer, de forma rigorosa, os valores para a linha de corte. Em trabalho futuro, pretende-se validar o instrumento, de forma que este possa ser usado não só para identificar domínios mais vulneráveis e que necessitem de uma intervenção didática mais consistente por parte de educadores e professores, mas também para auxiliar na deteção precoce de crianças que precisem de intervenção técnica mais especializada.

\section{Referências}

Agostinho, Celina (2020) The Acquisition of the Passive in European Portuguese. Tese de Doutoramento, Universitat Autònoma de Barcelona. 
Alves, Dina Caetano \& Ana Rita Carvoeiro (2019) Peace: Prova de Escrita para Avaliação e Análise de Competências de Escrita - contributos para o desenvolvimento da primeira versão do instrumento. Letras De Hoje 54 (2), pp. 231-242.

Capovilla, Alessandra, Fernando Capovilla \& Joceli Soares (2004) Consciência sintática no ensino fundamental: correlações com consciência fonológica, vocabulário, leitura e escrita. Psico-USF 9 (1), pp. 39-47.

Cardoso, Sónia \& Ana Castro (2012) Consciência de palavra em crianças de idade pré-escolar e escolar. Textos Selecionados, XXVII Encontro Nacional da Associação Portuguesa de Linguística, Lisboa: APL, pp. 136-152.

Costa, Ana Luísa, Armanda Costa \& Anabela Gonçalves (2017) Consciência linguística: aspetos sintáticos. In. M. J. Freitas \& A. L. Santos (eds.) Aquisição de língua materna e não materna: Questões gerais e dados do português. Berlin: Language Science Press, pp. 409-438.

Costa, João, Maria Lobo \& Carolina Silva (2011) Subject-object asymmetries in the acquisition of Portuguese relative clauses: Adults vs. children. Lingua 121, pp. 1093-1100.

Demont, Elisabeth \& Jean Emile Gombert (1996) Phonological awareness as a predictor of recoding skills and syntactic awareness as a predictor of comprehension skills. British Journal of Educational Psychology 66, pp. 315-332.

Duarte, Inês (2008) O conhecimento da língua: desenvolver a consciência linguística. Lisboa: DGIDC-ME.

Estrela, Antónia (2013) A Aquisição da Estrutura Passiva em Português Europeu. Tese de Doutoramento, FCSH-UNL.

Freitas, Maria João, Anabela Gonçalves \& Inês Duarte (2010) Avaliação da consciência linguística: aspetos fonológicos e sintáticos do português. Lisboa: Colibri.

Gough, Philip B. \& William E. Tunmer (1986) Decoding, reading, and reading disability. Remedial and Special Education 7, pp. 6-10.

Kirby, John R., Alain Desrochers, Leah Roth \& Sandy Lai (2008) Longitudinal predictors of word reading development. Canadian Psychology/Psychologie Canadienne 49 (2), pp. 103-110.

Ministério da Educação (2018) Aprendizagens essenciais - Português 1. ${ }^{\circ}$ ano. ME-DGE.

Pape, Kristine, Johan Bjørngaard, Steinar Westin, Turid Holmen \& Steinar Krokstad (2011) Reading and writing difficulties in adolescence and later risk of welfare dependence. A ten year follow-up, the HUNT Study, Norway. BMC Public Health 11, 718.

Perdigão, Ana (2015) Consciência Sintática: Processos de Concordância vs. Ordem de Palavras em PE. Tese de Mestrado, IPS, UNL.

Rego, Lúcia \& Lair Buarque (1997) Consciência sintática, consciência fonológica e aquisição de regras ortográficas. Psicologia: Reflexão e Crítica 10 (2), pp. 199-217.

Rodrigues, Lurdes, Isabel Alçada, Teresa Calçada \& João Mata (2017) Aprender a ler e a escrever em Portugal (relatório de progresso). Fórum Estatístico/DGEEC.

Schaars, Moniek, E. Segers \& L. Verhoeven (2019) Cognitive and linguistic precursors of early first and second language reading development. Learning and Individual Differences 72, pp. 1-14.

Silva, Isabel (coord.), Liliana Marques, Lurdes Mata \& Manuela Rosa (2016) Orientações curriculares para a educação pré-escolar. ME-DGE.

Smart, Diana, George J. Youssef, Ann Sanson, Margot Prior, John W. Toumbourou \& Craig A. Olsson (2017) Consequences of childhood reading difficulties and behaviour problems for educational achievement and employment in early adulthood. British Journal of Educational Psychology 87 (2), pp. 288-308.

Verdasca, José (coord.) (2019) Relatório PNPSE 2016-2018: Escolas e Comunidades tecendo Políticas Educativas com base em Evidências. Lisboa: PNPSE/DGE.

Viana, Fernanda L. \& Iolanda Ribeiro (2010) PRP - Prova de Reconhecimento de Palavras. Lisboa: Cegoc. 
Joana Batalha, Maria Lobo, Antónia Estrela e Bruna Bragança

Viana, Fernanda L., Carla Silva, Iolanda Ribeiro \& Irene Cadime (2017) Instrumentos de avaliação da linguagem: uma perspetiva global. In. M. J. Freitas \& A. L. Santos (eds.) Aquisição de língua materna e não materna: Questões gerais e dados do português. Berlin: Language Science Press, pp. 333-357.

Viana, Fernanda L., Iolanda Ribeiro, Sandra Santos, Irene Cadime, Celda Morgado \& Adriana Baptista (2018) Provas de rastreio $1 .^{\circ}$ ano. Versão 1. Editora Lusoinfo Multimédia. 